"Mircea cel Batran" Naval Academy Scientific Bulletin, Volume XIX - 2016 - Issue 1

Published by "Mircea cel Batran" Naval Academy Press, Constanta, Romania // The journal is indexed in:

PROQUEST / DOAJ / DRJI / JOURNAL INDEX / I2OR / SCIENCE LIBRARY INDEX / Google Scholar / Crossref /

Academic Keys / ROAD Open Access / OAJI / Academic Resources / Scientific Indexing Services / SCIPIO

\title{
CRITICAL INFRASTRUCTURE DEPENDENCY ON SPACE SYSTEMS
}

\author{
Alexandru GEORGESCU ${ }^{1}$ \\ Ulpia-Elena BOTEZATU2 \\ Alina-Daniela POPA ${ }^{3}$ \\ Ştefan POPA ${ }^{4}$ \\ Ştefan-Ciprian ARSENI ${ }^{5}$ \\ ${ }^{1} \mathrm{PhD}$ Cand. Scientific Researcher, EURISC Foundation, Bucharest \\ ${ }^{2}$ Scientific Researcher, Romanian Space Agency, Bucharest \\ ${ }^{3}$ Assistant Researcher, Military Equipment and Technologies Research Agency, Bucharest \\ ${ }^{4}$ Scientific Researcher, Cpt. Eng., Military Equipment and Technologies Research Agency, Bucharest \\ ${ }^{5}$ Scientific Researcher, Lt. Eng., Military Equipment and Technologies Research Agency, Bucharest \\ sarseni@acttm.ro, 16 Aeroportului street, Clinceni, Iffov
}

The work was supported by a grant of the Romanian National Authority for Scientific Research, CNDIUEFISCDI, project number 197/2012.

\begin{abstract}
Space systems are enablers of key applications which have become critical for the functioning of the infrastructure system-of-systems, especially from the perspective of risk governance efforts and $\mathrm{Cl}$ protection. Rapid innovation in space system cost, accessibility and applications has engendered various degrees of dependence on them. The critical dependencies are not evenly distributed throughout geographic areas, industries, infrastructure systems or national territory, even throughout the European Union. As for the critical aspect of dependencies, in which such interrelations lead to new vulnerabilities and the risk of cascading disruptions in complex systems, the greater emphasis on space systems has served to mitigate certain risks while encouraging others. Even in areas where space services remain a fact of tomorrow and criticality has not been achieved, it is the nature of interdependent critical infrastructures to enable propagation of space system disruption risk from areas which are, indeed, heavy users of space systems. Ultimately, the incentives for the use of space services are too great for the potential risks to deter usage, and it falls to responsible stakeholders (governments, providers, consumers, technical authorities and international organizations) to create the legislative and organizational framework and instruments for identifying and addressing the risks generated by the growing dependence on space systems.
\end{abstract}

Keywords: critical infrastructures, space systems, dependence, risk governance, complex systems.

\section{Introduction}

Space systems have become key enablers for a wide variety of commercial, scientific and military applications. The rapid growth of their capabilities has offset some of the size of the required investment and new developments promise an even greater reduction in the cost of space infrastructure. As such, some of the extant space systems have become deeply embedded in the functioning of advanced societies, supporting economies, lifestyles and governance processes. The increasing dependence on certain space systems places them firmly in the area of critical infrastructure, whose disruption or destruction would generate lasting damage. This inclusion into critical infrastructure theory is even more warranted as space systems have become a technological backbone for existing recognized critical infrastructures, such as energy, transportation, administration and others. The reliance of infrastructure systems-of-systems on space based command, coordination and control capabilities during normal functioning, but especially during emergency and crisis situation management processes, means that space systems fulfil the requirements for critical status. What is needed is to include space systems into the existing critical infrastructure protection framework, while also underlining the key differences between "terrestrial" infrastructures and extra-atmospheric ones. The geographic and economic realities of space systems also call for a different approach to protection efforts, based on international cooperation and collective action. The stakes for society are very high, as the previously identified critical infrastructure systems are growing ever more dependent on space capabilities for their normal functioning and for achieving greater efficiencies. This dependence is a source of new risks, vulnerabilities and threats.

\section{Space in the System-of-Systems}

The system-of-systems is a term denoting a complex array of socio-technical constructs which must work together to maintain a complex output, such as the required products or services for the maintenance of an advanced society, with the 


\begin{abstract}
"Mircea cel Batran" Naval Academy Scientific Bulletin, Volume XIX - 2016 - Issue 1
Published by "Mircea cel Batran" Naval Academy Press, Constanta, Romania /I The journal is indexed in: PROQUEST / DOAJ / DRJI / JOURNAL INDEX / I2OR / SCIENCE LIBRARY INDEX / Google Scholar / Crossref /

Academic Keys / ROAD Open Access / OAJI / Academic Resources / Scientific Indexing Services / SCIPIO
\end{abstract}

failure of one component being able to perturb the functioning of the whole and the continuity of its processes [7].

Although space systems are few in numbers and are continuously threatened by numerous manmade and environmental risks, space-based assets have a steadily increasing importance for economic, social or political activities within advanced and advancing societies. This dependency between societies and space systems is determined by the variety of important services that are being provided, based on capabilities such as: Earth Observation data, instantaneous communications or navigation all over the globe. Other services are also provided, with varying degrees of criticality, as well as serving in varying stages of the functioning of the system-of-systems. A space service may be consumed by a final user, or it may be an important intermediary product for the generation of the end-result, with its added value. The main reason for asserting the criticality of space systems is the idea that the destruction or disruption of these systems can have a substantial impact on quality of life or business continuity of a country, region, or of civilizations, leading to great costs both in human and economic terms, as well as the uncertainty regarding the required time for everything to reenter a normal state and whether that will even be possible.

Such abilities are conceptualized in the scientific literature of the field as resilience, robustness, reliability and others [8]. At the same time, interconnections between all of these critical infrastructure systems-of-systems, established not only at local or national level, but also at regional or international one, threaten to generate cascading disruptions in associated systems, enhancing the destructive potential of possible crises. The contagion of risk is not only done through geographic vectors, implying a geographic interdependency, but also through interdependencies of output, cybernetic and control systems interdependency, sector interdependencies and logical interdependencies [9].

The European Program for Critical Infrastructure Protection has the intention of identifying and protecting European critical infrastructures, in the same time with enforcing a set of minimal common standards for protecting critical infrastructures at national level for member countries. This Program has identified 11 domains of activity whose assets can be designated ascritical infrastructure systems. One of them is the economic exploitation of space; therefore this program is one of the first entities that took the initiative to define space-based systems as critical infrastructures. Other examples include: food security, water supply or the generation and delivery of electricity and other forms of energy.

This increasing dependence on specific space systems grants them a key position in the area of critical infrastructures, even though these systems are operating in the most hostile environment known to man and under strict economic imperatives and limitations. The presence of very serious specific threats, such as the risk of colliding with space debris and the full extent of the energies unleashed by space weather phenomena, increases the list of possible threats to space-based systems (and, in the latter case, to ground based systems as well).

All of the services that CSI render for humanity are performed by a limited pool of fragile space assets. According to the Union of Concerned Scientists' collaborative database on space systems, the millions of consumers and billions of beneficiaries of space capabilities are reliant on just over 1.300 space systems [10], which must cater to very different needs. Table 1 shows a breakdown of space systems by type and by originating countries.

This concentration of service capacity leads to unique opportunities for space economic development in the future, but also to the possibility of serious disruptions from the most random and limited occurrences.

The reliance of infrastructure systems-of-systems on space based information gathering, command, coordination and control capabilities during normal functioning, but especially during emergency and crisis situation management processes, means that space systems fulfill the requirements for critical status. This dependence transcends national borders, even though the assets themselves are considered to still be under the jurisdiction of their countries of origin and their motion and position preclude any territorial jurisdiction, making critical infrastructure protection activities much more difficult than in the case of localized terrestrial infrastructures. 
"Mircea cel Batran" Naval Academy Scientific Bulletin, Volume XIX - 2016 - Issue 1

Published by "Mircea cel Batran" Naval Academy Press, Constanta, Romania // The journal is indexed in: PROQUEST / DOAJ / DRJI / JOURNAL INDEX / I2OR / SCIENCE LIBRARY INDEX / Google Scholar / Crossref /

Academic Keys / ROAD Open Access / OAJI / Academic Resources / Scientific Indexing Services / SCIPIO

Table 1. Breakdown of space systems

\begin{tabular}{|c|c|c|c|c|c|c|c|c|c|c|c|c|}
\hline & \multicolumn{12}{|c|}{ Criteria } \\
\hline & \multicolumn{4}{|c|}{ Country } & \multicolumn{4}{|c|}{ Orbit } & \multicolumn{4}{|c|}{ Type (for US only) } \\
\hline & $\begin{array}{l}\text { United } \\
\text { States }\end{array}$ & Russia & China & Other & LEO & MEO & Elliptical & GEO & Civil & Commercial & Government & Military \\
\hline No. of satellites & 568 & 133 & 177 & 503 & 759 & 92 & 37 & 493 & 15 & 273 & 131 & 149 \\
\hline $\begin{array}{l}\text { Total No. of } \\
\text { satellites }\end{array}$ & \multicolumn{8}{|c|}{1,381} & \multicolumn{4}{|c|}{568} \\
\hline
\end{tabular}

\section{Critical Infrastructures and their Protection}

Critical Infrastructure Protection (CIP) is a set of disciplines and philosophies that, together, make up a framework that recognizes the critical nature of infrastructures, as well as their extensive interdependences. The materialization of risks is not easily prevented or its effects contained, and disruptions tend to propagate throughout the system-of-systems, triggering cascading failures in the provision of critical goods and services. So far, CIP has been applied at national level, with an increasing development in regional organizations, such as the EU and NATO, but only for terrestrial infrastructures. Space systems were relegated to a marginal position, compared with more existential systems facings severe threats, like energy, food, water and health. The criticality of space systems can no longer be ignored, and there is also the realization of the heavy dependence of previously mentioned critical infrastructures on space infrastructures, which provide command and control capabilities, information gathering, emergency response support and so on. For this reason, CIP precepts should be applied to critical space infrastructures (CSI) as well, identifying threats, mitigating vulnerabilities and minimizing disruptions. However, policy and decision makers should not just transpose CIP from terrestrial to space systems, as this would ignore the risks inherent in the heavy interconnections between the two. Rather, space systems should be integrated in existing CIP frameworks with the full realization of their importance, triggering developments in the fundamentals of critical infrastructure protection efforts around the world.

Timid progress has already been registered in building the legislative and institutional framework for critical space systems protection and development. The UN's Committee on the Peaceful Uses of Outer Space conducts varied research and regularly makes policy recommendations to member states regarding threats, opportunities and the implementation of new standards for achieving economic and security synergies. The United States, itself, is also an advanced actor, with the EU trailing not far behind. In the establishment and development of the European Programme for Critical Infrastructure Protection (EPCIP), space security has been present from the very beginning. Space was mentioned as one of the eleven critical infrastructures in Directive 114/2008 on the identification and designation of European critical infrastructures and the assessment of the need to improve their protection, and was subsequently mentioned in EU documents on preparedness for cyber-attacks (COM (2009) 149 and COM (2011) 163), space and cyber infrastructures being intimately linked to each other. Furthermore, space development and security was given special attention in $\operatorname{COM}(2011) 152$ - "Towards a space strategy for the European Union that benefits its citizens" and $\operatorname{COM(2011)~} 808$ Horizon 2020 - The Framework Programme for Research and Innovation.

\section{Critical Infrastructure Dependency on Space Systems}

Critical terrestrial infrastructures are dependent on space systems as providers of critical services, and one day maybe even goods. This dependency is increasing in size and scope, with both desirable and undesirable effects consequences. The desirable consequences are increased prosperity, better coordination of global infrastructure and supply chains, more accessible communication, better and more frequently updated information for improved decision making and others. The negative consequences are an increase in the exposure of critical terrestrial infrastructures to the risk that space systems will be destroyed or will malfunction. This places the entire system-of-systems at risk, because space systems have become an integral part of it, whether we consider them their own separate infrastructure or a component of each critical infrastructure sector in part. In truth, it is becoming difficult for decision makers and security experts to pinpoint where one infrastructure ends and another begins, because of the fluidity and the diffusiveness of modern infrastructure systems, which are more than simply physical assets in a precise geographic location. At the same time, transformation within the system-of-systems, due 


\section{"Mircea cel Batran" Naval Academy Scientific Bulletin, Volume XIX - 2016 - Issue 1 \\ Published by "Mircea cel Batran" Naval Academy Press, Constanta, Romania // The journal is indexed in: PROQUEST / DOAJ / DRJI / JOURNAL INDEX / I2OR / SCIENCE LIBRARY INDEX / Google Scholar / Crossref / \\ Academic Keys / ROAD Open Access / OAJI / Academic Resources / Scientific Indexing Services / SCIPIO}

to new capabilities and efficiencies, represent, from a security perspective, less of a clear progression towards more dependency and, thus, insecurity, and more of a mixed result where security decision makers hope that the security "ledger" ends up in the black. For instance, while dependency on space systems implies exposure to their risks, space systems are an important component of crisis and emergency situation management systems, as well as a tool for increased overall resilience. Whether the trade-off is worth it depends very much on circumstance, but political factors result in an overwhelming push towards the option that looks more like progress.

One way to analyze this trend of the growth of the use (and dependency on) space systems, in the absence of concrete data on number of users and beneficiaries and intensity of use, is to look at the evolution of the associated industries. According to the 2015 State of the Satellite Industry Report, commissioned by the Satellite Industry Association and researched by the Tauri Group [1], in 2014, the revenue of the satellite industry grew by $4 \%$ (more than doubling from where it was a decade earlier). This dynamic outstripped that of general global growth, and this is a trend which has been maintained irrespective of the vast and diffuse economic consequences of the 2008 World Financial Crisis. Some areas have seen yearly growth rates of $25 \%$, such as mobile data services. New technologies like CubeSats and more competition in launch services have led to 208 satellites being launched in 2014 (63\% of which were CubeSats), as opposed to 107 in 2013.

The dependency mentioned before, of CIS (Critical Infrastructure Systems) on space systems, is increasing because of a number of reasons that we will briefly present in the following paragraphs.

Firstly, the economic equations of access to space are changing, removing or ameliorating some of the previously high barriers to entry in the space industry. The cost of space assets is steadily being reduced, while the capabilities are being improved. The cost of access to space is also falling due to increased competition and technological innovation, with certain developments on the horizon that may fundamentally change the industry. The cost of financing and insurance is also falling, because of a better understanding of the risks involved, a better risk profile and the gradual formation of a framework for commercial activity that addresses uncertainties like liability and so on.

Secondly, competition and interconnectedness between states mandate the eventual adoption of the best means for improving performance and productivity. Currently, space systems are a potential source for important productivity gains (just in time inventory management, increasing the intensity of use of existing capacity of ports and airports without lessening security, precision agriculture etc.), so they must eventually be incorporated by any actor wishing to remain competitive.

Thirdly, newly developing countries are increasingly skipping certain critical infrastructure developments and going straight to their spacebased replacements, in order to reduce upfront costs and develop quicker. Regardless of whether this is economically advisable, or wise from a security standpoint, the truth is that rapidly developing nations are, for instance, foregoing installing landline communication in favor of wireless communications, and going straight to digital shopping, payments and banking without physical infrastructure that would have been present in the developed nations at least as legacy systems. Meanwhile, already developed nations have pre-existing infrastructure systems which are still economically usable or have not been amortized, so full spectrum reliance on space systems can still be an issue of geographic or sectorial patchwork applications.

There are also a few issues to consider, when it comes to the dependency that space systems engender. There is the mainline or direct criticality of the space system to each of its dependent critical infrastructures. There is circumstantial criticality, where circumstances or environmental factors determine whether the relationship between the space system and the $\mathrm{Cl}$ is an even more important and potentially dangerous one and the disruption or destruction of the space systems would cause significant hardship to the $\mathrm{Cl}$ in question. For instance, satellite communications may be replaced in quotidian usage, but not if an extreme weather phenomena makes them the only reliable means of command and coordination. There is also an indirect criticality arising from the chain of interconnections with other critical infrastructures. A security actor might have managed to eliminate the critical dependence of the infrastructure he is responsible for on space systems, only to find out that cascading disruptions during a negative event are propagating through the entire system-ofsystems and eventually affecting his infrastructure as well, despite the absence of an immediate connection. A useful example is that of a country dependent on less productive forms of agriculture. It does not use precision agriculture, nor does it steward its natural resources with the aid of information collected through satellites. It should 


\section{"Mircea cel Batran" Naval Academy Scientific Bulletin, Volume XIX - 2016 - Issue 1 \\ Published by "Mircea cel Batran" Naval Academy Press, Constanta, Romania /I The journal is indexed in: PROQUEST / DOAJ / DRJI / JOURNAL INDEX / I2OR / SCIENCE LIBRARY INDEX / Google Scholar / Crossref / \\ Academic Keys / ROAD Open Access / OAJI / Academic Resources / Scientific Indexing Services / SCIPIO}

be more or less immune to space infrastructure disruption. However, when it comes time for the farmers of the country to obtain loans, to insure crops or to transport their crops to market, especially international ones, they are utilizing critical infrastructures which are dependent on space systems - the financial infrastructure and the international transport infrastructure. This means that they are experiencing an indirect, but still appreciable and measurable dependency.

It stands to reason therefore that all critical infrastructures, whether considered as a whole or as individual assets, present a critical space infrastructure risk mix which describes the channels through which the risk of their malfunctioning is transmitted. And this risk mix will be formed from the risk related to direct dependencies, indirect or second order dependencies and, finally, tertiary dependencies. These dependencies become increasingly difficult to describe, explain and measure the farther out we go from the initial infrastructure within the system-of-systems.

Various methods have been formulated to attempt to describe dependency issues, and many of them are applicable to critical space infrastructure dependency as well. The increasing complexity of the relationships also calls for further advances in the field of visualization, as well as modeling and simulation capacity. One method is a quantitative approach regarding the level of services which are provided by space systems or one particular systems and their proportion to the whole, although this method favors communication systems at the expense of circumstantially critical systems such as weather satellites. Another method is by analyzing the monetary flows between separate infrastructure systems, using economic exchange as a means of gauging relative importance and, therefore, criticality. Australia has used this method to describe its critical infrastructure interconnections, for instance in the case of agriculture and the level of its dependence on other infrastructure systems [2]. Establishing the reliance on space systems involves a subset of this data, as well.

What does this dependency mean for resilience governance processes, especially given the global reach of space systems and the widespread reliance on a very low number of such assets? It means, mainly, that this is a collective problem whose only solution lies in finding a collective approach to managing risks, vulnerabilities and threats. National efforts are welcome and likely to be the backbone of such efforts, given that the most resources and organizational capacities are devoted to Critical Infrastructure Protection efforts at national levels. However, an overreliance on individual efforts allows for the formation of gaps in security to which security decision makers will be blind, given informational asymmetries. Cooperation at near global levels is important for adequately gauging risks, for legitimizing a global approach to standards, commitments to sustainable practices that limit the creation of new debris and dispose of systems at the end of their lifespan etc. Neither should this be an exclusive effort on the part of spacefaring nations, though they do have a technological and financial advantage. It is important for all countries recognizing their dependence to support a framework which takes their needs and concerns into account. Issues of sovereignty, liability, stakeholder involvement and jurisdiction will complicate attempts at global governance, but the alternative is an uncoordinated mess of interests, ideas and bad incentives.

\section{CONCLUSION}

The final paragraphs of this brief introduction in critical space infrastructure issues are dedicated to staking out a position for Romania on the issue of its critical dependence on space systems. Romania is an active and advanced user of Critical Infrastructure Protection efforts, with a good track record at European levels for implementing best practices and ensuring a competitive national critical infrastructure system that is coherent with EPCIP and is open to the latest advancements. With regard to space systems, Romania is in a challenging position, of having to consider its dependence on and the security of systems which it does not own and over which it has no sovereignty or direct legal authority. Romania is not a spacefaring nation, but it is a nation whose development and prosperity are increasingly tied to the availability of space services at the right time, at the right price and in the right quantity. Anything that threatens one or more of these coordinates either harms Romania or its future development. Its dependence will only grow, though the security impact may be mitigated partially by new developments in the field of space system resilience. However, Romania must consider the means by which it can protect its interests:

Firstly, Romania must, to the extent that it is possible without sacrificing growth and development, to limit its critical dependence on space systems and possess adequate substitutes for at least the critical portion of its space services consumption. It must foster resilience in the face of disruptive events and their tendency to lead to cascading interruptions in the functioning of the infrastructure system-of-systems. Training key 


\begin{abstract}
"Mircea cel Batran" Naval Academy Scientific Bulletin, Volume XIX - 2016 - Issue 1
Published by "Mircea cel Batran" Naval Academy Press, Constanta, Romania /I The journal is indexed in: PROQUEST / DOAJ / DRJI / JOURNAL INDEX / I2OR / SCIENCE LIBRARY INDEX / Google Scholar / Crossref /

Academic Keys / ROAD Open Access / OAJI / Academic Resources / Scientific Indexing Services / SCIPIO
\end{abstract}

personnel is very important, as well as the hardening of key terrestrial systems not just from the after effects of the loss of space services, but also from the effects of threats such as Space Weather.

Secondly, it must utilize its limited ability to influence and encourage proper risk and resilience governance in the field. The Romanian leadership of the UN Committee on the Peaceful Uses of Outer Space, which, among others, develops technical standards and recommendations for increasing space system resilience and minimizing the susceptibility to threats such as debris, is an obvious example. Another is Romania's membership in the Europeans Space Agency. By contributing its perspectives and that of other countries like it to the development process of new space systems, it can ensure that these systems will, to the extent possible, reflect the concerns and also service the needs of non-spacefaring and smaller states. For instance, the Galileo GNSS system is both interoperable with the main GNSS network, the American GPS and Russian GLONASS [3] (which cannot operate with each other), but it is also devoid of military oversight which, in the case of the other systems, can dictate the limiting of service provision (and quality) to civilian users, including allies, in the case of ill-defined national emergencies and other interests. Another example is the Copernicus/GMES program of creating a constellation of remote sensing satellites. Given the significant costs of accessing information collected through Earth Observation satellites, their user base is smaller than it could be. However, Copernicus features an innovative business model, which includes free access to data of certain quality [4]. So far, this is a model applied only to specific applications in the developing world, aimed at environmental preservation and sustainable agriculture [5]. The success of those projects warrants an adaptation of their principles to address the needs of medium income countries such as Romania.

Thirdly, Romania should pursue a path of ensuring privileged access to critical space services. This involves identifying the capabilities required (emergency services, government communication, data gathering for military purposes etc.) and charting a course to ensure the predictability of the supply of such services. Romania could, for instance, pursue contracts and agreements that would include having a certain guaranteed level of service, even if the occurrence of a negative event were to reduce the available capacity for space services, Romania should also carefully consider taking advantage of the boom in the space industry, both in technology and business, to create its own providers of critical space services capacity. It could prioritize certain applications and embark on a longer term build-up of redundant capacity through the use of CubeSats, group launches, private sector economies of scale and so on, enabling a space program at the fraction of the cost just a few years ago. Japan's replacement of its ALOS remote sensing satellite, which malfunctioned during the Fukushima crisis, with a constellation of Nano satellites providing more and better services at a lower cost and with greater redundancy, stands as a valuable example [6].

Finally, Romania must ensure that it is cognizant of its vulnerability to the tertiary impact of space system disruption, which is the vulnerability transmitted through its allies' and commercial partners' dependence on space systems.

In this article, we have merely summarized the main points for an argumentation in favor of considering space systems as critical infrastructures, requiring inclusion into existing Critical Infrastructure Protection frameworks and paradigms. Certain space systems warrant their designation as critical, being important enabler for applications critical for the proper functioning of an advanced and interconnected world. Their disruption or destruction would cause significant damage to the infrastructure system-of-systems, translating into material and human losses at the level of our societies, and a blow to investor and consumer confidence worldwide in a global world. They are faced with a challenging security environment, involving both natural and man-made threats, as well as continuous environmental pressures that may cause spontaneous disruptions. They have an array of specific threats as well, such as Space Weather and Space Debris, but are also increasingly vulnerable to human disruption efforts, through the development and proliferation of anti-satellite weaponry and technology. The critical links between terrestrial infrastructures and between critical space infrastructures and the traditional infrastructures that have already been defined are undergoing close study, but possess a troubling complexity which renders them opaque. With modeling and simulation capabilities having been declared critical national resources by the US Congress, there is a renewed drive to address the risks, vulnerabilities and threats we face through the lens of Critical Infrastructure Protection, to which space systems are becoming a valuable addition. This addition is being acknowledged through specific research programs, inclusion in Conference agendas and through contributions to the profile of these issues in the general media. 
"Mircea cel Batran" Naval Academy Scientific Bulletin, Volume XIX - 2016 - Issue 1

Published by "Mircea cel Batran" Naval Academy Press, Constanta, Romania // The journal is indexed in:

PROQUEST / DOAJ / DRJI / JOURNAL INDEX / I2OR / SCIENCE LIBRARY INDEX / Google Scholar / Crossref /

Academic Keys I ROAD Open Access / OAJI / Academic Resources / Scientific Indexing Services / SCIPIO

\section{BIBLIOGRAPHY:}

[1] Tauri Group, "2015 State of the Satellite Industry Report", commissioned by Satellite Industry Association, published September 2015. Available at: http://www.sia.org/wp-content/uploads/2015/06/Mktg15-SSIR-2015FINAL-Compressed.pdf.

[2] N. Nguyen et al, "Infrastructure and Australia's food industry: Preliminary economic assessment", Australian Bureau of Agricultural and Resource Economics and Sciences, report 13.13, November 2013, Canberra. Available at: http://data.daff.gov.au/data/warehouse/9aap/2013/iafipead9aap_20131105/infaAust FoodInd_prelimEcoAssess_v1.0.0.pdf.

[3] European Space Agency website,

http://www.esa.int/Our_Activities/Navigation/Galileo_and_EGNOSaccessed 5 March 2016.

[4] European Space A $g e n c y$, "Free access to Copernicus satellite data", published 15 November 2013 , http://www.esa.int/Our_Activities/Observing_the_Earth/Copernicus/Free_access_to_Copernicus_Sentinel_sa tellite_data.

[5] W.Archy, "Satellite technologies used to aid fisheries", EarthZine (Fostering Earth Observation \& Global Awareness), July 2011. Available at: http://www.earthzine.org/2011/07/14/satellite-technologies-aidingfisheries/.

[6] T.Iwasa, "Disaster monitoring activities in Japan" presentation. Available at:http://www.unoosa.org/pdf/pres/stsc2012/tech-11E.pdf.

[7] S.Bouchon, "The Vulnerability of interdependent Critical Infrastructures Systems: Epistemological and Conceptual State-of-the-Art", pg, 42, EC Directorate General Joint Research Centre, Institute for the Protection and Security of the Citizen, Luxembourg, 2006.

[8] P.Hokstad, I. B. Utne, J.Vatn, "Risk and Interdependencies in Critical Infrastructures", pg 16-18, Springer Series in Reliability Engineering, Springer, Trondheim, Norway, 2012, ISBN 978-1-4471-4661-2.

[9] A. V. Gheorghe, M.Schläpfer - "Critical Infrastructures: Ubiquity of Digitalization and Risks of Interdependent Critical Infrastructures", IRGC - ETH Document, June 2004, Zürich.

[10] Union of Concerned Scientists, "UCS Satellite Database". Available at: http://www.ucsusa.org/nuclearweapons/space-weapons/satellite-database.html\#.VmXWInYrLIV (Accessed on 20.04.2016). 